\title{
Effect of a dietary supplement containing kurozu (a Japanese traditional health drink) concentrate on several obesity-related parameters in obese Japanese adults: a randomized, double-blind, placebo-controlled trial
}

\author{
Naobumi Hamadate ${ }^{1}$, Ken-ichiro Nakamura ${ }^{1 *}$, Motoko Hirai ${ }^{1}$, Tetsuro Yamamoto ${ }^{2}$, \\ Hideyo Yamaguchi ${ }^{2}$, Muneaki Iizuka ${ }^{2}$, Etsushi Yamamoto ${ }^{2}$, Yoshitaka Iwama ${ }^{3}$, and \\ Kazunaga Yazawa ${ }^{4}$
}

${ }^{1}$ Department of Research and Development, Egao Co. Ltd., 1-47 Higashihonmachi, Higashi-ku, Kumamoto, Kumamoto 862-0902, Japan; ${ }^{2}$ Research Center, TTC Co. Ltd., 1-20-2 Ebisunishi, Shibuya-ku, Tokyo 113-0021, Japan; ${ }^{3}$ Nihonbashi Cardiology Clinic, 13-4 NihonbashiKodenmacho, Chuo-ku, Tokyo 103-0001, Japan; ${ }^{4}$ Laboratory of Nutraceuticals and Functional Foods Science, Tokyo University of Marine Science and Technology, 4-5-7 Konan, Minato-ku, Tokyo 108-8477, Japan

Corresponding author: Ken-ichiro Nakamura, Department of Research and Development, Egao Co. Ltd., 1-47 Higashihonmachi, Higashi-ku, Kumamoto, Kumamoto 862-0902, Japan

Submission date: March 7, 2013; Acceptance date: August 2, 2013; Publication date: August 9, 2013

\section{ABSTRACT:}

Objective: This study was undertaken to examine the Kurozu concentrate (KC) based dietary supplement on several obesity-related parameters in obese Japanese male and female adults.

Background: Kurozu, which is a specific type of rice vinegar produced by fermentation of unpolished brown rice, has long been used as a traditional health food and folk medicine in Japan. A recent animal study and our preliminary human study suggest that the KC supplement has potential for use in the management of obesity.

Materials and Methods: A 12-week, randomized, double-blind, placebo-controlled trial was conducted involving 48 Japanese adult subjects (28 males and 20 females) with obesity. Subjects were either assigned to the group consuming the KC supplement for 12 weeks $(870 \mathrm{mg} /$ day; 480 $\mathrm{mg} /$ day as KC) ( $\mathrm{n}=24 ; 14$ males and 10 females) or the placebo group ( $\mathrm{n}=24 ; 14$ males and 10 females). All test participants were assessed using several obesity-related parameters, including body weight, BMI, waist circumference, and abdominal fat computed tomography (CT) sections. These measurements took place at baseline and at week 12 .

Results: At week 12, a significant decrease in body weight $(\mathrm{P}<0.043)$ and nearly significant 
decreased values of $\mathrm{BMI}(\mathrm{P}=0.052)$ were observed in the $\mathrm{KC}$ group compared to the placebo group. The reduction in waist circumference at week 12 within the $\mathrm{KC}$ group was not significantly greater than the placebo group. Examination of abdominal CT sections around the navel indicated that, although most of the values of the total fat area, subcutaneous fat area, and visceral fat area for both of the placebo and KC groups significantly increased during the 12week intervention, the magnitude of increase in the total fat area for all subjects and that of the total fat area, subcutaneous fat area, and visceral fat area for females on one or more of three CT sections were significantly lower in the $\mathrm{KC}$ group than the placebo group $(\mathrm{P}<0.05)$.

Conclusion: Although the results are not definitive, $\mathrm{KC}$ supplementation may have potential for improving some obesity-related parameters in obese subjects, particularly females.

Key words: Kurozu concentrate $(\mathrm{KC}), \mathrm{KC}$-based dietary supplement (KC supplement), abdominal obesity-related parameters, body mass index (BMI), computed tomography (CT), abdominal fat

\section{BACKGROUND:}

Accumulating epidemiological data indicate that obesity is significantly associated with increased risks of the three major lifestyle-related conditions, viz., dysglycemia, dyslipidemia, and hypertension, all of which can cause premature death [1-3]. A cluster of these medical conditions is known as the metabolic syndrome [4]. There are also data suggesting that obesity, particularly abdominal obesity, combined with hyperglycemia, hyperlipidemia and/or hypertension, becomes an immediate precursor to cardiovascular disease (CVD) [5, 6]. Therefore, improvement of obesity is an important health goal for obese individuals in order to prevent and/or treat the metabolic syndrome and CVD.

Currently, using an anthropometric parameter referred to as the "body mass index (BMI)", the World Health Organization (WHO) defines obesity as any value above $30 \mathrm{~kg} / \mathrm{m}^{2}$ and preobesity (overweight) as the values between 25 and $30 \mathrm{~kg} / \mathrm{m}^{2}$ [7]. According to this definition, the prevalence of obesity among the whole population of Europe and the United States is estimated to be $5-27 \%$ [7, 8], while obesity is less prevalent (2-3\%) among Japanese people [9]. However, Japanese individuals appear more likely to develop the above-mentioned metabolic syndrome or lifestyle-related chronic diseases. There are numerous epidemiological studies showing that the prevalence of type 2 diabetes is similar in Japanese individuals (10-12\%) [10] to Westerners (8$12 \%)[11,12]$. In addition to the incidence of diabetes, other obesity-associated diseases are also significantly greater among Japanese adults with BMI values above $25 \mathrm{~kg} / \mathrm{cm}^{2}$ than those with lower BMI values. Based on these data, the Japan Society for the Study of Obesity adopted a lower cutoff of BMI (Japanese criteria of obesity: $\geqq 25 \mathrm{~kg} / \mathrm{m}^{2}$ ), consequently leading to an increase in obesity prevalence figures in Japan [13].

Kurozu, is produced from brown rice with rice malt through static-surface fermentation in the southernmost district of Kyushu island (Kagoshima Prefecture) of Japan. This unique type of fermentative product has been used for a long time as a traditional health drink and folk medicine in this country. Kurozu is biochemically characterized by various amino acids, vitamins, acetic 
acid, other organic acids, and proteins as its major ingredients [14], together with several phenolic acid compounds, such as vanillic acid, sinapic acid, and ferulic acid, along with two unique radical scavenging compounds, dihydroferuic acid and dihydrosinapic acid [15], as its minor ingredients. One of the leading health food companies in Japan, Egao Co. Ltd. (Kumamoto, Japan), has developed a capsular product of Kurozu containing KC as the active ingredient. $\mathrm{KC}$ is made through concentration under a reduced pressure with heating, followed by freeze-drying with the addition of rice powder as a vehicle, followed by pulverizing. The composition of resulting powdery $\mathrm{KC}$ is basically similar to that of original Kurozu, except for a slight loss of acetic acid and some other organic acids.

Recently, Tong et al. reported that oral doses of Kurozu concentrated liquid are effective in decreasing the adipocyte size via inhibition of intestinal absorption of dietary fat in Sprague Dawley (SD) rats [16]. A similar change in adipocyte size distribution induced by Lactobacillusfermented milk has been associated with the prevention of obesity development in SD rats and obese Zucker rats $[17,18]$. Thus, we were led to the postulation that $\mathrm{KC}$ may have anti-obesity potential when given to humans. To investigate this possibility, a feeding study was performed with subjects, Japanese adults with BMIs between 25 and 30, using a commercial product containing powdery $\mathrm{KC}$ as the potential active component.

\section{METHODS:}

Subjects: Thirty-two male and 20 female Japanese subjects, aged 30-65 and 40-65 years, respectively, with BMI between 25 and $30 \mathrm{~kg} / \mathrm{cm}^{2}$, body weight $<100 \mathrm{~kg}$ and waist circumference $\geqq 85 \mathrm{~cm}$ (males) and $\geqq 90 \mathrm{~cm}$ (females) were voluntarily recruited from Tokyo, Japan. Individuals were excluded if they were: currently attempting to lose body weight (i.e., participating in an exercise program designed for weight loss, or taking supplements or health foods associated with weight management or changes in appetite); taking medicines or health foods that potentially alter the body fat, serum lipids, and/or lipid metabolism; routinely using dietary supplements enriched with $\mathrm{KC}$ and/or unrefined Kurozu; receiving medically supervised treatment for any serious diseases; with diabetes or any other disease that requires immediate and/or regular medication; with a history of allergy to the test product; pregnant, breast feeding, or of childbearing potential; or participating in another clinical study within the last month.

Study design and dietary intervention: A prospective, randomized, placebo-controlled, parallel design feeding trial was performed. After evaluation of eligibility criteria, study subjects were instructed not to change their regular dietary habits and their current exercise program for the duration of 12 week study.

All eligible subjects were randomly assigned to receive either 3 capsules of the $\mathrm{KC}$ supplement or the placebo each day for 12 weeks. A 290 mg-capsule of the KC supplement contained $160 \mathrm{mg}$ powdery $\mathrm{KC}, 30 \mathrm{mg}$ powdery fermentation precipitates, $97 \mathrm{mg}$ crystalline cellulose, and $2 \mathrm{mg}$ calcium stearate. A daily dose of 6 capsules of the $\mathrm{KC}$ supplement containing $480 \mathrm{mg}$ powdery $\mathrm{KC}$ used in the present study was chosen on the basis of our preliminary study data showing that a substantial weight reduction can be seen in slightly obese adults after taking more than 2 capsules of the $\mathrm{KC}$ supplement (160 mg as powdery $\mathrm{KC}$ ) per day. Powdery fermentation precipitates rich in various amino acids and peptides were added to the supplement 
for its nutritional enrichment. A placebo capsule containing only crystalline cellulose (228 $\mathrm{mg}$ ) and calcium stearate $(2 \mathrm{mg}$ ) was prepared so as to be indistinguishable from the $\mathrm{KC}$ supplement capsule in appearance and packaging. The product was kept hidden from the study subjects and the study coordinator. All subjects were required to take 3 allocated capsules once a day after breakfast with the aid of approximately $180 \mathrm{ml}$ of water. Taking less than $85 \%$ of the prescribed course of the allocated capsule was considered as non-compliance with the intervention. Such non-compliant subjects were to be excluded from the efficacy assessment.

Anthropometrics: Height was measured at the beginning of the study. Body weight and waist circumference were measured and BMI was calculated before the start and after the end of the 12-week intervention (baseline and week 12, respectively). At these 2 time points, abdominal xray computed tomography (CT) was performed to measure body fat areas with all the subjects in a spine position (ROBUSTO-Ei, Hitachi Medical Co., Japan 120 kV, $200 \mathrm{~mA}$ ). Fat area was calculated using built-in software. Total subcutaneous and visceral fat areas were measured on 1 cross-sectional scan image obtained at the navel, at $1 \mathrm{~cm}$ above the navel and at $1 \mathrm{~cm}$ below the navel.

Food intake and exercise behavior: Subjects were strongly advised not to change their regular dietary habits for the duration of the study. Food and beverage intake was measured via selfreport for preceding 3 days at the baseline, as well as at weeks 4,8 and 12, and analyzed using a software program (Calorie Checker Ver. 5, Techno Science, Tokyo, Japan). Those subjects, whose estimated energy intake at any time point after the start of intervention increased or decreased by $30 \%$ or above compared with the values at the baseline were removed from the efficacy analysis.

All subjects were advised not to change their regular exercise habits during the study period. The extent of current exercise or physical activity was represented by measures of a passometer for the preceding 3 days of the baseline and at weeks 4,8 , and 12 .

Blood and urine sampling and testing: Fasting blood samples were collected by venopuncture at the baseline and at weeks 4,8 , and 12 in EDTA tubes. Plasma samples obtained after a centrifugation at $1,000 \times \mathrm{g}$ for $10 \mathrm{~min}$ at $4^{\circ} \mathrm{C}$ were kept at $-80^{\circ} \mathrm{C}$ until analysis. The hematological and blood biochemical variables analyzed included: white blood cells, red blood cells, hemoglobin, hematocrit, platelets, total protein, albumin, total cholesterol, high density lipoprotein (HDL) cholesterol, low density lipoprotein (LDL) cholesterol, triglycerides (TG), glucose, total bilirubin, alkaline phosphatase, aspartate transaminase, alanine aminotransferase, lactate dehydrogenase, $\gamma$-glutamyltransferase, blood urea nitrogen, creatinine, uric acid, sodium, potassium, and chloride. Urine samples were collected for the analysis of qualitative protein, qualitative glucose, qualitative occult blood, and $\mathrm{pH}$.

Ethics: This study adhered to all guidelines set forth in the Declaration of Helsinki (amended in 2008) and the Ethical Guidelines for Epidemiological Research (enacted by the Japanese Government in 2004). Ethical approval was obtained from the Nihonbashi Cardiovascular Clinic Ethics Committee (reference number: 23719). Written informed consent was obtained from all subjects prior to starting the study. To ensure privacy, all records were identified with an anonymous subject identification number. 
Safety assessments: Safety parameters were the incidence and severity of intervention-related adverse events reported by the subjects that they had experienced, as well as of abnormal change in hematological and/or blood biochemical variables, during the 12-week intervention.

Statistical analysis: Results are presented as the mean \pm standard error of the mean (SEM). Only data from the subjects completing the study protocol were included for analysis. Clinical and anthropometric variables were compared between the subjects in the placebo and $\mathrm{KC}$ groups via Student's unpaired $t$ test. The Student's paired $t$ test was used to assess the within-group difference between data collected at the baseline and those at week 12. The Student's unpaired $t$ test was used for the between-group comparison of changes from baseline that were calculated by subtracting the baseline value from the value at week 12 . When $\mathrm{P}$ was $<0.05$, the differences observed were considered statistically significant.

\section{RESULTS:}

Subjects: Forty-eight individuals (28 males and 20 females) eligible for the protocol were enrolled in the study and assigned to either the placebo capsules ( $n=24 ; 14$ males and 10 females) or the KC supplement capsules ( $\mathrm{n}=24 ; 14$ males and 10 females). Although all subjects completed the study, 3 subjects in the placebo group (1 male and 2 females) and 2 in the $\mathrm{KC}$ group ( 1 male and 1 female) were excluded from the efficacy analysis for the reason that the dietary total energy per day averaged during the 12-week intervention period changed from the baseline by $30 \%$ or above. The ingestion rate for both of the placebo and $\mathrm{KC}$ groups was $98.3 \%$ of capsules provided.

Based on the study diary, self-reported food intake including total energy during the 12week intervention period was examined. Group mean values for the placebo and KC groups were: total energy, 2,034 \pm 51 and 1,937 $\pm 62 \mathrm{kcal} /$ day, respectively; protein, $70.0 \pm 2.0$ and 69.1 $\pm 2.5 \mathrm{~g}$ /day, respectively; fat, $30.4 \pm 1.0$ and $30.7 \pm 1.2 \% \mathrm{kcal}$ (relative to total energy), respectively; and carbohydrate, $49.0 \pm 1.4$ and $49.8 \pm 1.4 \%$ kcal (relative to total energy), respectively. All of the values met recommended intakes of total energy and individual macronutrients as reported in the National Health and Nutrition Survey in Japan, 2011 (Ministry of Health, Labour and Welfare, Japan). Moreover, the data showed that there was no significant between-group difference in the mean value of total energy and macronutrient intakes. Likewise, there was no significant over-time (baseline versus week 12) or between-group difference in passometer measurement results (baseline, placebo: 8,165 \pm 674 steps/day versus KC: 8,289 \pm 882 steps/day; week 12, placebo: 8,078 \pm 589 steps/day versus $\mathrm{KC}: 8,208 \pm 604$ steps/day) (all: $\mathrm{P}>0.05)$.

Efficacy assessment: Table 1 shows the effect of the $\mathrm{KC}$ supplement on body weight, BMI, and waist circumference in all subjects, as well as in males and females, over the 12-week intervention in comparison with the placebo. In results obtained with all subjects, there was a significant increase in the mean body weight for the placebo group $(\mathrm{P}<0.05)$, whereas the value for the KC group was scarcely changed. This between-group difference in the change from baseline led to a significant level $(\mathrm{P}=0.043)$. A similar trend in the change of mean BMI from baseline was also observed within the individual groups, with a likely significant between-group 
difference $(\mathrm{P}=0.052)$. When analyzing males and females separately, a between-group difference in body weight or BMI did not reach a significant level. The KC supplement intake did not seem to have substantial effect on waist circumference in either male or female subjects.

Table 1. Data on anthropometric parameters at the baseline and week 12 of the intervention with placebo or $\mathrm{KC}$ in all subjects ( $\mathrm{n}=21$ for placebo and 22 for $\mathrm{KC})$, males $(\mathrm{n}=13$ each for placebo and $\mathrm{KC}$ ) and females ( $\mathrm{n}=8$ for placebo and 9 for $\mathrm{KC}$ )

\begin{tabular}{|c|c|c|c|c|c|}
\hline \multirow{2}{*}{ Variables } & \multirow{2}{*}{$\begin{array}{l}\text { Population } \\
\text { Analyzed }\end{array}$} & \multirow{2}{*}{ Time points } & \multicolumn{2}{|c|}{ Measurements $^{\mathrm{a}}$} & \multirow{2}{*}{$\begin{array}{l}\text { Between-group difference } \\
\text { in variance }(\mathbf{P} \text {-value })\end{array}$} \\
\hline & & & Placebo group & $\mathrm{KC}$ group & \\
\hline \multirow[t]{3}{*}{ Height $(\mathrm{cm})$} & All subjects & Baseline & $165.7 \pm 2.3$ & $164.2 \pm 2.1$ & \\
\hline & Males & Baseline & $171.5 \pm 2.0$ & $171.1 \pm 1.7$ & \\
\hline & Females & Baseline & $156.1 \pm 2.8$ & $154.3 \pm 1.0$ & \\
\hline \multirow[t]{11}{*}{ Body weight (kg) } & All subjects & Baseline & $74.9 \pm 2.1$ & $74.4 \pm 2.0$ & \\
\hline & & Week 12 & $75.6 \pm 2.2^{b}$ & $74.4 \pm 2.0$ & \\
\hline & & Change & $0.79 \pm 0.29$ & $-0.02 \pm 0.26$ & 0.043 \\
\hline & & & & & \\
\hline & Males & Baseline & $78.9 \pm 2.3$ & $80.1 \pm 2.2$ & \\
\hline & & Week 12 & $79.4 \pm 2.5$ & $80.0 \pm 2.2$ & \\
\hline & & Change & $0.52 \pm 0.38$ & $-0.14 \pm 0.31$ & 0.191 \\
\hline & & & & & \\
\hline & Females & Baseline & $68.3 \pm 3.0$ & $66.2 \pm 1.4$ & \\
\hline & & Week 12 & $69.5 \pm 3.0^{\mathrm{b}}$ & $66.4 \pm 1.3$ & \\
\hline & & Change & $1.23 \pm 0.41$ & $0.17 \pm 0.46$ & 0.109 \\
\hline \multirow[t]{9}{*}{ BMI $\left(\mathrm{kg} / \mathrm{cm}^{2}\right)$} & All subjects & Baseline & $27.2 \pm 0.3$ & $27.5 \pm 0.3$ & \\
\hline & & Week 12 & $27.5 \pm 0.4$ & $27.5 \pm 0.3$ & \\
\hline & & Change & $0.29 \pm 0.11$ & $0.00 \pm 0.10$ & 0.052 \\
\hline & Males & Baseline & $26.8 \pm 0.4$ & $27.3 \pm 0.4$ & \\
\hline & & Week 12 & $26.9 \pm 0.4$ & $27.3 \pm 0.4$ & \\
\hline & & Change & $0.16 \pm 0.13$ & $-0.05 \pm 0.10$ & 0.216 \\
\hline & Females & Baseline & $27.9 \pm 0.5$ & $27.8 \pm 0.5$ & \\
\hline & & Week 12 & $28.4 \pm 0.5$ & $27.9 \pm 0.4$ & \\
\hline & & Change & $0.50 \pm 0.17$ & $0.07 \pm 0.20$ & 0.122 \\
\hline \multirow[t]{11}{*}{$\begin{array}{l}\text { Waist circumference } \\
(\mathrm{cm})\end{array}$} & All subjects & Baseline & $95.4 \pm 1.2$ & $95.2 \pm 1.4$ & \\
\hline & & Week 12 & $94.8 \pm 1.4$ & $94.7 \pm 1.4$ & \\
\hline & & Change & $-0.61 \pm 0.50$ & $-0.58 \pm 0.27$ & 0.954 \\
\hline & Males & Baseline & $93.9 \pm 1.2$ & $93.5 \pm 1.8$ & \\
\hline & & Week 12 & $92.6 \pm 1.3$ & $92.6 \pm 1.9$ & \\
\hline & & Change & $-1.25 \pm 0.57$ & $-0.87 \pm 0.38$ & 0.578 \\
\hline & & & & & \\
\hline & Females & Baseline & $97.9 \pm 2.4$ & $97.8 \pm 1.8$ & \\
\hline & & Weeks 12 & $98.3 \pm 2.6$ & $97.6 \pm 1.8$ & \\
\hline & & Change & $0.42 \pm 0.86$ & $-0.17 \pm 0.35$ & 0.514 \\
\hline & & & & & \\
\hline
\end{tabular}


${ }^{a}$ Values are expressed as the mean \pm standard error of the mean (SEM). ${ }^{b} \mathrm{P}<0.05$ against the baseline (paired Student's $t$ test). KC, Kurozu concentrate; BMI, bady mass index.

The regional assessment on the effect of 12-week intervention with the $\mathrm{KC}$ supplement on body fat was initially performed by measuring the total fat area, subcutaneous fat area, and visceral fat area on abdominal CT sections at the navel. As shown in Table 2, when analyses were performed on all subjects (including males and females separately) the mean values of all the total fat area, subcutaneous fat area, and visceral fat area (for both of the placebo and $\mathrm{KC}$ groups) increased significantly $(\mathrm{P}<0.01$ or $\mathrm{P}<0.05)$ or insignificantly but substantially at the end of 12-week intervention compared with baseline. The only exception was the subcutaneous fat area for females in the $\mathrm{KC}$ group. However, the extent of the increase in value of these abdominal fat-related parameters for the $\mathrm{KC}$ group generally appeared to be greater than that for the placebo group; significant between-group differences in the change compared to baseline were seen with the total fat area for all subjects $(\mathrm{P}=0.038)$, females $(\mathrm{P}=0.009)$, and the subcutaneous fat area for females $(\mathrm{P}=0.033)$. It looks likely, therefore, that the $\mathrm{KC}$ supplement may exhibit a greater anti-adiposity activity in females than males. To further examine this possibility, the abdominal fat parameters were measured on 2 additional CT sections around the navel, i.e, at $1 \mathrm{~cm}$ above the navel and at $1 \mathrm{~cm}$ below the navel. As illustrated in Figure 1, compared to the placebo, the KC supplement significantly suppressed an increase of the total fat area in 2 of the $3 \mathrm{CT}$ sections (at the navel and $1 \mathrm{~cm}$ below the navel) for all subjects $(\mathrm{P}<0.05)$ and for females $(\mathrm{P}<0.01)$. No such significant suppressive effect on the total fat area was seen in any CT sections for males on the KC supplement. Moreover, in 1 or more CT sections, significant suppression of the subcutaneous fat area $(\mathrm{P}<0.05$, at the navel and $1 \mathrm{~cm}$ below the navel) and visceral fat area $(\mathrm{P}<0.01$, at $1 \mathrm{~cm}$ below the navel), were observed in females on the $\mathrm{KC}$ supplement. However, this effect was not observed in male subjects or all subjects.

No significant between-group differences in values of blood lipids (LDL cholesterol, HDL cholesterol and TG), fasting blood glucose, or systolic and diastolic blood pressures, were observed at the end of the 12-week intervention (data not shown).

Safety assessment: The KC supplement and the placebo supplement were well tolerated. Although 9 of 24 subjects (38\%) ingesting the KC supplement and 14 of 24 subjects (58\%) consuming the placebo, once at least, reported some gastrointestinal adverse events, such as gastralgia, abdominal pain, and diarrhea. All of these self-reported events were very mild in intensity, occurred only temporarily, and were judged by the investigator as unrelated to the intervention. 
Table 2. Data on abdominal fat-related parameters at the baseline and week 12 of the intervention with placebo or $\mathrm{KC}$ in all subjects $(\mathrm{n}=21$ for placebo and 22 for $\mathrm{KC})$, males $(\mathrm{n}=13$ each for placebo and $\mathrm{KC}$ ) and females ( $\mathrm{n}=8$ for placebo and 9 for $\mathrm{KC}$ )

\begin{tabular}{|c|c|c|c|c|c|}
\hline \multirow{2}{*}{ Variables } & \multirow{2}{*}{$\begin{array}{c}\text { Population } \\
\text { analyzed }\end{array}$} & \multirow{2}{*}{$\begin{array}{l}\text { Time } \\
\text { points }\end{array}$} & \multicolumn{2}{|c|}{ Measurements $\left(\mathrm{cm}^{2}\right)^{\mathrm{a}}$} & \multirow{2}{*}{$\begin{array}{c}\text { Between-group } \\
\text { difference in variance } \\
\text { (P-value) }\end{array}$} \\
\hline & & & $\begin{array}{l}\text { Placebo } \\
\text { group }\end{array}$ & $\mathrm{KC}$ group & \\
\hline \multirow[t]{9}{*}{ Total fat } & \multirow[t]{3}{*}{$\begin{array}{l}\text { All } \\
\text { subjects }\end{array}$} & Baseline & $310.6 \pm 17.2$ & $314.3 \pm 16.0$ & \\
\hline & & Week 12 & $\underset{\mathrm{b}}{339.0 \pm 17.6}$ & $\underset{b}{328.4 \pm 17.6}$ & \\
\hline & & Change & $28.3 \pm 5.6$ & $14.0 \pm 3.8$ & 0.038 \\
\hline & \multirow[t]{3}{*}{ Males } & Baseline & $281.7 \pm 15.7$ & $281.5 \pm 17.8$ & \\
\hline & & Week 12 & $\underset{\mathrm{c}}{301.5 \pm 15.3}$ & $\underset{\mathrm{c}}{294.0 \pm 21.3}$ & \\
\hline & & Change & $19.8 \pm 6.9$ & $12.5 \pm 5.6$ & 0.422 \\
\hline & \multirow[t]{3}{*}{ Females } & Baseline & $357.7 \pm 32.1$ & $361.8 \pm 21.9$ & \\
\hline & & Week 12 & $\begin{array}{c}399.0 \pm 28.6 \\
\mathrm{~b}\end{array}$ & $\underset{\mathrm{b}}{377.9 \pm 22.2}$ & \\
\hline & & Change & $42.2 \pm 7.7$ & $16.2 \pm 4.54$ & 0.009 \\
\hline \multirow[t]{9}{*}{ Subcutaneous fat } & \multirow[t]{3}{*}{$\begin{array}{l}\text { All } \\
\text { subjects }\end{array}$} & Baseline & $198.0 \pm 17.0$ & $212.6 \pm 16.1$ & \\
\hline & & Week 12 & $\underset{\mathrm{c}}{206.4 \pm 17.7}$ & $215.0 \pm 17.0$ & \\
\hline & & Change & $8.5 \pm 2.4$ & $2.4 \pm 2.6$ & 0.093 \\
\hline & \multirow[t]{3}{*}{ Males } & Baseline & $157.0 \pm 9.9$ & $172.0 \pm 17.4$ & \\
\hline & & Week 12 & $162.0 \pm 10.5$ & $176.3 \pm 19.8$ & \\
\hline & & Change & $5.1 \pm 2.4$ & $4.3 \pm 3.4$ & 0.857 \\
\hline & \multirow[t]{3}{*}{ Females } & Baseline & $264.6 \pm 29.6$ & $271.4 \pm 16.4$ & \\
\hline & & Week 12 & $\underset{\mathrm{b}}{278.6 \pm 29.1}$ & $270.9 \pm 18.5$ & \\
\hline & & Change & $14.0 \pm 4.6$ & $-0.5 \pm 4.1$ & 0.033 \\
\hline \multirow[t]{8}{*}{ Visceral fat } & \multirow[t]{2}{*}{$\begin{array}{l}\text { All } \\
\text { subjects }\end{array}$} & Baseline & $112.7 \pm 8.0$ & $101.7 \pm 6.2$ & \\
\hline & & $\begin{array}{l}\text { Week } 12 \\
\text { Change }\end{array}$ & $\begin{array}{c}132.5 \pm 6.8^{\mathrm{c}} \\
19.8 \pm 3.9\end{array}$ & $\begin{array}{c}113.4 \pm 5.8^{\mathrm{c}} \\
11.6 \pm 2.7\end{array}$ & 0.088 \\
\hline & \multirow[t]{3}{*}{ Males } & Baseline & $124.8 \pm 10.4$ & $109.6 \pm 8.6$ & \\
\hline & & Week 12 & $\underset{\mathrm{b}}{139.5 \pm 10.0}$ & $117.8 \pm 8.7^{\mathrm{b}}$ & \\
\hline & & Change & $14.7 \pm 5.4$ & $8.2 \pm 2.9$ & 0.301 \\
\hline & \multirow[t]{3}{*}{ Females } & Baseline & $93.1 \pm 9.6$ & $90.4 \pm 7.4$ & \\
\hline & & Week 12 & $121.3 \pm 6.6^{\mathrm{b}}$ & $107.0 \pm 6.6^{\mathrm{b}}$ & \\
\hline & & Change & $28.2 \pm 4.1$ & $16.6 \pm 4.7$ & 0.086 \\
\hline
\end{tabular}


baseline (paired Student's $t$ test). KC, Kurozu concentrate.
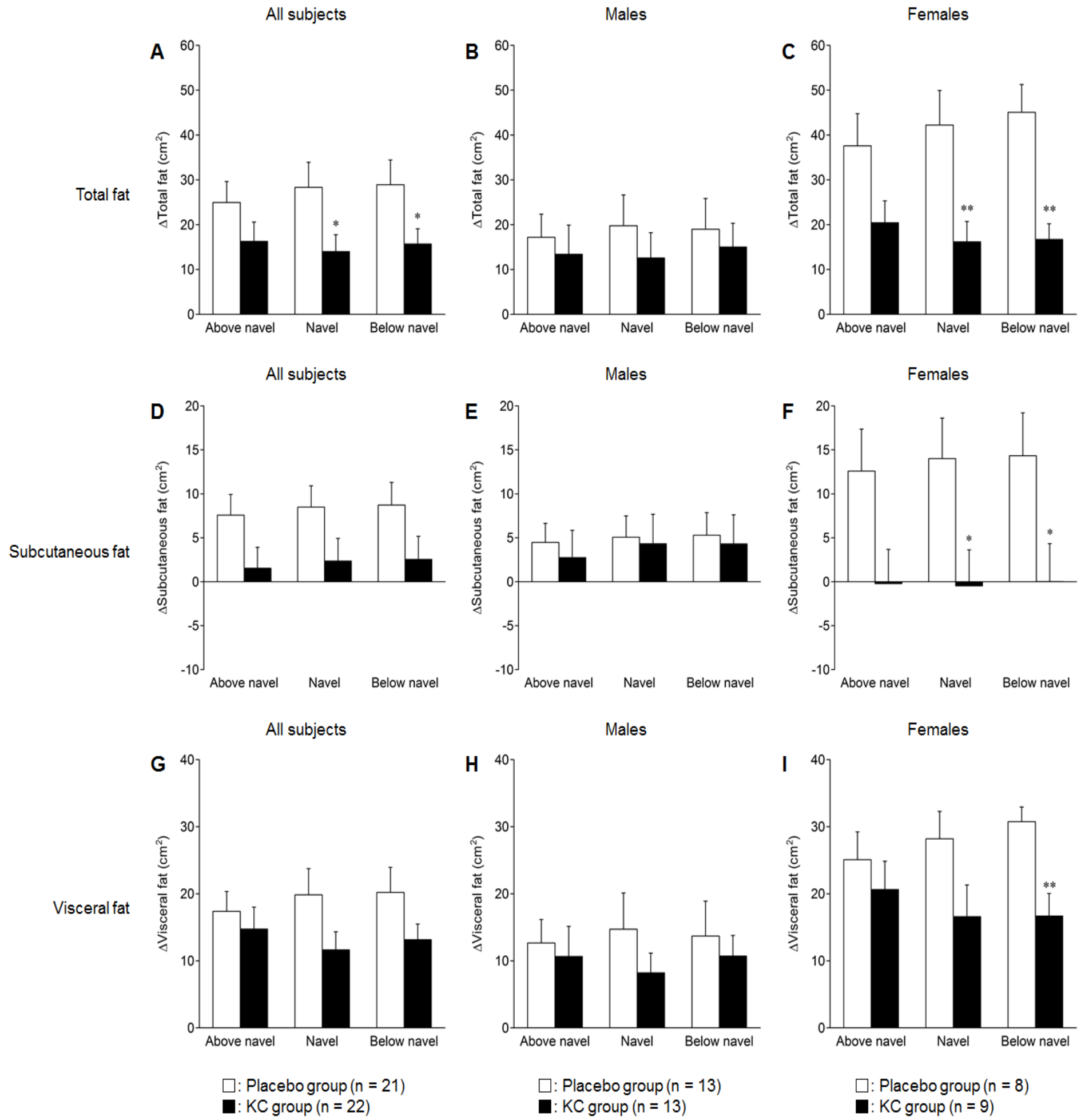
Figure 1. Changes from the baseline in the total fat area $(A, B, C)$, subcutaneous fat area (D, E, F) and visceral fat area $(\mathrm{G}, \mathrm{H}, \mathrm{I})$ at $1 \mathrm{~cm}$ above the navel, at the navel and at $1 \mathrm{~cm}$ below the navel for all subjects $(A, D, G)$, males $(B, E, H)$ and females $(C, F, I)$ after the end of the 12-week intervention with placebo $(\square)$ or $\mathrm{KC}$ supplement $(\boldsymbol{\square})$. Values for the $\mathrm{KC}$ group were compared with those for the placebo group: $* \mathrm{P}<0.05$; and $* * \mathrm{P}<0.01$.

\section{DISCUSSION:}

This feeding study suggests the beneficial effect of $\mathrm{KC}$ supplementation on several factors relevant to obesity or abdominal adiposity in obese Japanese adults, particularly females. In the whole study population, which consisted of both males and females, daily ingestion of $870 \mathrm{mg}$ of the $\mathrm{KC}$ supplement ( $480 \mathrm{mg}$ as $\mathrm{KC}$ ) over 12 weeks was associated with a significant reduction in body weight and a close-to-significant suppressive effect on BMI that were accompanied with a significant suppression of the apparent increment of the total fat area measured at the navel and below the navel, compared to the placebo. Moreover, in female subjects consuming the $\mathrm{KC}$ supplement, a significant suppressive effect on the total fat area (at the navel and below the navel), as well as the subcutaneous fat area (at the navel and below the navel) and visceral fat area (below the navel) was observed. Different from this, the KC supplement had no appreciable effect on blood lipids (total cholesterol, LDL cholesterol and TG) or fasting blood glucose. Thus, we are led to the postulation that the anti-adiposity potential of the $\mathrm{KC}$ supplement may not link with any lipid or glucose metabolisms but be more closely associated with suppression of adipogenesis.

This possibility could be supported by the findings of Tong and co-workers, who demonstrated from their animal study with Sprague-Dawley rats that ingestion of Kurozu concentrated liquid (KCL) decreases the adipocyte size via inhibition of dietary fat absorption without effect on the levels of any serum, hepatic lipids, or serum glucose [16]. These investigators also demonstrated that KCL significantly inhibits pancreatic lipase activity in vitro and concluded that KCL acts to suppress adipogenesis through inhibition of pancreatic lipasemediated intestinal dietary fat absorption. Presumably, KC may also be considered to have a similar adipogenesis-suppressive action because of its sharing of common chemical properties with KCL.

It remains to be answered which compound(s) actually is/are implicated in the putative anti-adiposity effect of KC. One candidate compound is acetic acid, a main component of wine vinegar. Acetic acid is contained in most conventional vinegars at a concentration of 3-9\% [19]. There are reported human studies demonstrating that daily intake of a drink containing $15 \mathrm{~mL}$ apple vinegar (750 $\mathrm{mg}$ as acetic acid) for 12 weeks is effective in reducing the blood cholesterol and triglyceride levels as well as improving obesity [20,21]. The exclusive contribution of acetic acid to the beneficial anti-hyperlipidemic and anti-obesity effects of vinegar observed in humans has been verified by several animal studies [20, 22-24]. However, the amount of acetic acid actually contained in the daily dose of $\mathrm{KC}$ used in this study (approx. $20 \mathrm{mg}$ as acetate) is far less than that for the preceding human studies using apple vinegar. Therefore, acetic acid is likely unresponsible for the anti-adiposity potential of the $\mathrm{KC}$ supplement.

Another group of candidate compounds present in $\mathrm{KC}$ are several phenolic acids, such as 
vanillic acid, sinapic acid, and ferulic acid; these compounds are known to show inhibitory activity against pancreatic lipase [25]. Considering this, in conjunction with an animal study on KCL which demonstrated the association of its in vivo activity to suppress adipogenesis with its in vivo inhibition of pancreatic lipase-mediated dietary lipid absorption [16], these phenolic acids are likely implicated in $\mathrm{KC}$-induced body fat reduction. Further in vitro and in vivo studies will be warranted to examine whether this is the case or not.

This study has some limitations. First, the number of subjects enrolled in both the placebo and $\mathrm{KC}$ groups was small, this may have decreased the study's ability to detect significant differences between the 2 groups when analyzed. Second, since the chemical structure of $\mathrm{KC}$ is not yet understood in detail, we were unable to specify the exact component(s) of KC causing its nutraceutical effects. Extended larger studies are needed to assess the potential of this KC-based dietary supplement for improving adiposity in obese subjects.

\section{CONCLUSION:}

The results of the present comparative study with the test and placebo groups have demonstrated that a daily supplementation of 480-mg KC lowered (improved) several obesity-related parameters, including body weight, BMI and abdominal fat areas on CT sections, with significant between-group differences, in obese Japanese subjects, particularly females, following an 12-week treatment. The $\mathrm{KC}$ supplement was well tolerated without any clinically significant side-effects. It looks likely, therefore, that the $\mathrm{KC}$ supplement may have certain benefits as a complementary therapy for obese individuals.

Competing interests: The authors have no financial interests or conflicts of interests.

Author's contributions: All authors contributed to this study.

Abbreviations: BMI, body mass index; CT, computed tomography; HDL, high density lipoprotein; KC, Kurozu concentrate; KC supplement, KC-based dietary supplement; KCL, Kurozu concentrated liquid; LDL, low density lipoprotein; SD, Sprague Dawley; SEM, standard error of the mean; TG, triglycerides; WHO, World Health Organization;

\section{REFERENCES:}

1. Higgins M, Kannel W, Garrison R, Pinsky J, Stokes J $3^{\text {rd }}$. Hazards of obesity-the Framingham experience. Acta Med Scand 1998;222:23-26.

2. Manson JE, Stampfer MJ, Hennekens CH, Willett WC. Body weight and longevity. A reassessment. JAMA 1987;257:353-358.

3. Pi-Sunyer FX. Medical hazards of obesity. Ann Intern Med 1993;119:655-660.

4. Grundy SM. Inflammation, hypertension, and the metabolic syndrome. JAMA 2003;290:3000-3002.

5. Mensah G.A, Mokdad AH, Ford E, Narayan KM, Giles WH, Vinicor F, et al. Obesity, metabolic syndrome, and type 2 diabetes: emerging epidemics and their cardiovascular implications. Cardiol Clin 2004;22:485-504. 
6. Rexrode KM, Carey VJ, Hennekens CH, Walters EE, Colditz GA, Stampfer MJ, et al. Abdominal adiposity and coronary heart disease in women. JAMA 1998;280:1843-1848.

7. Word Health Organization. Obesity: preventing and managing the global pidemic. Report of a WHO consultation. World Health Organ Tech Rep Ser 2000;894:i-xii, 1-253.

8. Flegal KM, Carroll MD, Ogden CL, Johnson CL. Prevalence and trends in obesity among US adults, 1999-2000. JAMA 2002;288:1723-1727.

9. Yoshiike N, Matsumura Y, Zaman MM, Yamaguchi M. Descriptive epidemiology of body mass index in Japanese adults in a representative sample from the National Nutrition Survey 1990-1994. Int J Obes 1998;22:684-687.

10. Islam MM, Horibe H, Kobayashi F. Current trend in prevalence of diabetes mellitus in Japan, 1964-1994. J Epidemiol 1999;9:155-162.

11. Harris MI, Flegal KM, Cowie CC, Eberhardt M.S, Goldstein DE, Little R, et al. Prevalence of diabetes, impaired fasting glucose, and impaired glucose tolerance in U.S. adults: the Third National Health and Nutrition Examination Survey, 1988-1994. Diabetes Care 1998;21:518-524.

12. Mooy JM, Grootenhuis PA, de Vries H, Valkenburg HA, Bouter LM, Kostense PJ et al. Prevalence and determinants of glucose intolerance in a Dutch caucasian population: The Hoorn Study. Diabetes Care 1995;18:1270-1273.

13. Japan Society for the Study of Obesity. Japanese Guidelines for Diagnosis of Obesity. J Japan Soc Study Obes 2011;17:1-78.

14. Haruta S, Ueno S, Egawa I, Hashiguchi K, Fujii A, Nagano M et al. Succession of bacterial and fungal communities during a traditional pot fermentation of rice vinegar assessed by PCR-mediated denaturing gradient gel electrophoresis. Int J Food Microbiol 2006;109:7987.

15. Shimoji Y, Tamura Y, Nakamura Y, Nanda K, Nishidai S, Nishikawa Y et al. Isolation and identification of DPPH radical scavenging compounds in Kurosu (Japanese unpolished rice vinegar). J Agric Food Chem 2002;50:6501-6503.

16. Tong L-T, Katakura Y, Kawamura S, Baba S, Tanaka Y, Udono M et al. Effects of Kurozu concentrated liquid on adipocyte size in rats. Lipids Health Dis 2010;9: 134.

17. Hamad EM, Sato M, Uzu K, Yoshida T, Higashi S, Kawakami H et al. Milk fermented by Lactobacillus gasseri SBT 2055 influences adipocyte size via inhibition of dietary fat absorption in Zucker rats. Brit J Nutr 2009;101:716-724.

18. Sato M, Uzu K, Yoshida T, Hamad EM, Kawakami H, Matsuyama H et al. Effects of milk fermented by Lactobacillus gasseri SBT 2055 on adipocyte size in rats. Brit J Nutr 2008;99:1013-1017.

19. Ren H, Endo H, Watanabe E, Hayashi T. Chemical and sensory characteristics Chinese, Korean, and Japanese vinegars. J Tokyo Univ Fish 1997;84:1-11.

20. Fushimi T, Suruga K, Oshima Y, Fukihara M, Tsukamoto Y, Goda T. Dietary acetic acid reduces serum cholesterol and triacylglycerols in rats fed a cholesterol-rich diet. Brit J Nutr 2006;95:916-924.

21. Kondo S, Kishi M, Fushimi T, Ugazin S, Kaga T. Vinegar intake reduces body weight, body fat mass, and serum triglyceride levels in obese Japanese subjects. Biosci Biotechnol Biochem 2009;73:1837-1843. 
22. Kondo T, Kishi M, Fushimi T, Kaga T. Acetic acid increases in gene expression of fatty acid oxidation enzymes in liver and suppresses body fat accumulation. J Agric Food Chem 2009;57:5982-5986.

23. Sakakibara S, Yamaguchi T, Oshima Y, Tsukamoto Y, Kadowaki T. Acetic acid activates hepatic AMPK and reduces hyperglycemia in diabetic KK-A(y) mice. Biochem Biophys Res Commun 2006;344:597-604.

24. Yamashita H, Fujisawa K, Ito E, Idei S, Kawaguchi N, Kimoto M et al. Improvement of obesity and glucose tolerance by acetate in Type 2 diabetic Otsuka Long-Evans Tokushima Fatty (OLETF) rats. Biosci Biotechnol Biochem 2007;71: 1236-1243.

25. Karamać M, Amarowicz R. Inhibition of pancreatic lipase by phenolic acids: examination in vitro. Z Naturforsch 1996;51:90-95. 